Article

\title{
Fad or Trend? Rethinking the Sustainability of Connected Health
}

\author{
Sonia Chien-I Chen ${ }^{1}\left(\mathbb{D}\right.$, Chenglian Liu ${ }^{2}(D)$ and Ridong $\mathrm{Hu}^{1, *}$ \\ 1 Institute of Quantitative Economics, Huaqiao University, Xiamen 361021, Fujian, China; \\ drsoniachen@mail.com \\ 2 School of Computing, Neusoft Institute of Guangdong, Foshan 528225, Guangdong, China; \\ chenglian.liu@gmail.com \\ * Correspondence: j_rdhu@hqu.edu.cn
}

Received: 24 January 2020; Accepted: 24 February 2020; Published: 27 February 2020

check for updates

\begin{abstract}
Policymakers, academics, and industry players have been focused on determining whether connected health $(\mathrm{CH})$ is a fad or a trend by looking at its sustainability. Although the significance of innovation in healthcare is gradually rising, a definitive identification and systematic comprehension of the core drivers, structure, content, and pattern of innovation in $\mathrm{CH}$ are missing. To bridge this gap, this study re-examines and analyses $\mathrm{CH}$ from the perspectives of its industrial chain and structure, to assess its future prospects and sustainability by focusing on how its structures and participants act in the ecosystem. This study involves an inductive theory building approach based on multi-stage, semi-structured interviews ( $\mathrm{n}=60$ in total). The results indicate that the core drivers, constituents, and components of $\mathrm{CH}$ need to be identified and restructured. A valid discourse, which is missing in the current literature, should be proposed with regard to the sustainability of $\mathrm{CH}$. A sustainable business model innovation (BMI) system and the methods employed to achieve sustainability are suggested to discover indicators for future success. This study enriches the current $\mathrm{CH}$ understanding from a technology perspective and suggests some implications for practitioners as well as policymakers to enhance sustainable development in the healthcare sector.
\end{abstract}

Keywords: sustainability; connected health; fad; trend; value; business model innovation; ageing society; tele-healthcare; and Taiwan

\section{Introduction}

Due to the adversities encountered by an ageing society, connected health $(\mathrm{CH})$ is emerging as an alternative technological measure that allows healthcare to be provided remotely, to increase efficiency, cost-effectiveness, and satisfaction for healthcare recipients [1,2]. However, there is a controversy regarding whether $\mathrm{CH}$ is a fad or a trend, which has led to an increased focus on its business sustainability [3-7]. In this study, the sustainability of $\mathrm{CH}$ is defined as the ability to exist, be self-sufficient, and coexist in an ecosystem, wherein the exploitation of resources, direction of investments, orientation of technological development, and institutional change are all in harmony and enhance both current and future potential to meet human needs and aspirations [8,9].

Business sustainability often confirms the need for change and innovation in companies' current business model (BM) $[10,11]$. This is apparent in a novel discourse regarding $\mathrm{CH}$, with increasing concern about sustaining businesses. $\mathrm{CH}$ is proposed as a promising, effective solution to ageing population issues in healthcare; however, its performance and outcomes are still controversial, despite the fact that it has been practised for decades $[12,13]$. As such, it is important to understand what is preventing the full effectiveness of $\mathrm{CH}$. 
This study aims to rethink and discuss the industrial chain and structure of $\mathrm{CH}$ to assess its future and sustainability. It focuses on how its structures and participants act in the ecosystem to bridge the gaps in business sustainability. In fact, whether its structure is loosely or tightly coupled and whether its participants are active may affect $\mathrm{CH}^{\prime}$ s sustainability. The review and analysis in this study found that the root causes of $\mathrm{CH}$ unsustainability are the lack of core drivers of business sustainability, appropriate content structures, and patterns of innovation. This study contributes to the existing literature by exploring the nature of $\mathrm{CH}$ in the Taiwanese context to discover crucial elements of sustaining $\mathrm{CH}$ business. The key findings suggest a rethinking of the business model innovation (BMI) in $\mathrm{CH}$ and subsequent analysis, integration, and redefinition of its elements. This study then develops a value-centric business model innovation system (VCBMIS) as a solution. However, the analysis of its underlying patterns is left to future research.

\section{Literature Review}

$\mathrm{CH}$ applications are efficient solutions to improve health care services [14,15]. This study references the essential literature to identify the knowledge gaps within $\mathrm{CH}$ and aims to define a reusable requirements repository for sustainable, $\mathrm{CH}$ applications based on the innovation of BM's elements. The literature review of this study adopted the convergence and business model innovation concept to provide a concise and up-to-date review that accounts for the influence of technology and social phenomena [16]. Current literature on $\mathrm{CH}$ implementation is emergent and has illustrated how technology enables a more connected healthcare system; specifically, the improvement of healthcare accessibility, cost-effectiveness, and quality of life [17-20]. Nevertheless, there are many unexplored areas relating to business sustainability in terms of quality, cost, increased technology, and future development in $\mathrm{CH}$ [21]. In general, critical issues can be summarized as follows: cost (finance) [22,23], infrastructure [24,25], technology [22,26], business sustainability [27], and collaboration and integration [28,29]. There are divergent interests between $\mathrm{CH}$ industries, the government, and consumer stakeholders in $\mathrm{CH}$ in relation to these issues, with the key issue being CH's sustainability [30,31].

\subsection{Current Status and Issues in Connected Health}

In this study, $\mathrm{CH}$ is an umbrella term for the family of applied healthcare solution technologies that aim to alleviate shortages of healthcare professionals while controlling cost, increasing efficiency, and maintaining quality [22]. Research in $\mathrm{CH}$ is timely and relevant. Indeed, most societies are already deep into an era characterized by an ageing population and multiplying healthcare needs. An initial review of $\mathrm{CH}$ in this study reveals that most research focused on its performance in terms of cost-effectiveness and efficiency $[1,3,6,14,22]$. This study further explores the relationship between technology and wellness, and the optimization of this relationship within the macro environment.

In brief, $\mathrm{CH}$ arose as a result of three factors. First, there is a tendency to pursue excellence in healthcare, such as by promoting and monitoring quality, efficiency, safety, and customer service $[1,32,33]$. Health professionals and institutions desire better access, quality, and efficiency of care $[34,35]$. Second, costs are rapidly increasing due to the ageing population, an increase in chronic conditions, better survival rates among patients fighting serious diseases, and longer lifespans [36,37]. The healthcare economy has thus become more dynamic than in the past [38]. Third, increasing provider shortages and other relevant challenges, such as the geographic dispersion of families and troubling ethnic disparities in the provision and quality of care, are very significant concerns [39]. A further source of pressure in healthcare is the demand for better service by paying customers. The development of consumerism in healthcare may be a catalyst for patient-centric healthcare [40-42]. These factors together have created a stronger impetus to force innovation, both from inside and outside the system.

An overview of $\mathrm{CH}$ implementation in the US and EU illustrates how technology enables a more connected system in healthcare and its societal benefits [22,43]. Healthcare services can thereby be 
extended to distant populations with significant cost-saving outcomes for certain chronic conditions [44]. Quality improvement and fewer or less severe caregiver shortages are evident. These benefits overlap in improvements to healthcare accessibility, cost-effectiveness, and quality [32-35]. Many international $\mathrm{CH}$ pilot schemes show application feasibility; however, the cost saving is not significant. The universally successful implementation of $\mathrm{CH}$ care remains an open issue [45]. This lack of evidence in support of sustainable $\mathrm{CH}$ suggests that some challenges remain, despite the evidence of application benefits from the US and the EU.

Although the significance of innovation in healthcare is gradually rising, a definitive identification and systematic comprehension of the core drivers, structure, content, and pattern of innovation in $\mathrm{CH}$ are still missing. Researchers still need to bridge this gap. This study reviews innovation methods to identify appropriate means to design and clarify an innovation pattern in $\mathrm{CH}$.

\subsection{Innovation Methods}

First, selecting an appropriate innovation type depends on an organization's aims and objectives. The literature indicates that the main issues in healthcare systems generally concern cost, quality, and accessibility. Indeed, innovation does play a significant role in sustaining growth and economic development [46], which makes the selection of innovation methods more critical to success. The literature review also suggests that the issues in $\mathrm{CH}$ are relevant to the lack of innovation in BMs [47]. Thus, it is essential to identify an appropriate innovation type and method to resolve these issues. This study adopts disruptive innovation because the ineffectiveness of traditional methods in healthcare increases the need for different solutions. Healthcare is relatively conservative compared to other business sectors, although numerous innovations have existed for decades, with much sustaining innovation to reduce the risk of failure $[48,49]$. These innovations focus solely on allocating and managing health resources $[47,50]$. Consequently, the outcomes of innovation do not translate into satisfying results.

Second, the confined application in technology innovation limits its effectiveness. Over the past 30 years, the demand for innovative treatments and equipment to improve the quality of life often increased health expenditures significantly [51,52]. Although many innovations have been applied, they mainly evolved to be employed in products, services, and processes. Consequently, they serve only limited outcomes and may not always help reduce cost while maintaining quality. Reaching such aims seems to require a broader application of technological innovation.

Third, any fundamental and effective changes will involve the healthcare system's stakeholders [47]. To make healthcare innovation effective, industry players, funding, public policy, technology, customers, and accountability all have essential roles [53]. Because the healthcare sector is a complex mix of multiple stakeholders and cross-departments, it requires a more radical level of innovation to address these diverse requirements successfully.

Finally, there is evidence on how to apply disruptive innovation to healthcare in a manner that has already been proven to be feasible and has contributed to effective healthcare [54-56]. The telemedicine-based institution, one of the $\mathrm{CH}$ models, is indeed a disruptive $\mathrm{BM}$ for diagnostic activities and supports the argument that disruptive innovation can work in healthcare with significant outcomes [57]. Therefore, disruptive innovation is suitable for this study because it is more likely to meet the objectives of enabling more affordable, accessible, and efficient healthcare while maintaining quality.

The nature of disruptive innovation and its beneficial adaptation to healthcare is of considerable interest in this study. Most innovations focus on technology since innovation was initially the responsibility of the research and development departments [58]. Although technological innovation is remarkable and representative, as many companies have succeeded with innovative BMs that depend on advanced technology, it is not in itself the primary purpose of innovation. Moreover, Christensen et al. [47] believe that 'disruptive innovation' can permeate to firms' or hospitals' BMIs, which contributes to both the affordability and quality of healthcare. 
The use of innovation in this study focuses on the need to rethink the BM in the $\mathrm{CH}$ ecosystem by changing the role of the customer and the industrial chain structure, which may fundamentally and radically alter the approach [58]. This makes this study different from other studies that merely summarize and analyse the current BMs in $\mathrm{CH}$. According to Chesbrough [59], the BM mediates the technical and economic domains, and therefore, it may be meaningful to investigate the liaison between technological development and economic impacts in healthcare through the BMI. In short, the BM can be a vehicle for delivering innovation while being an element of innovation simultaneously.

\section{Research Methodology}

In this section, the research methodology will be justified and research design for collecting data will be described, followed by data analysis and research validity. The methodology of the research is based on the formulated review questions and objectives.

\subsection{Research Method}

This study employed an exploratory approach based on multi-stage, semi-structured interviews ( $\mathrm{n}=60$ in total) to address the study's aim and research question. The research question is to discern whether $\mathrm{CH}$ is a fad or a trend from the perspective of sustainability. Factors of the core drivers, structure, content, and pattern of innovation are considered as review protocols in order to rethink its sustainability. A better understanding of an emergent discourse, such as $\mathrm{CH}$, through a qualitative methodology exploring its nature by insightful inputs, wider discussion, and synthesis of diverse opinions can be facilitated to bridge the knowledge gaps in the literature [60]. Taiwan was selected for the case study exploring the development of $\mathrm{CH}$ sustainability and the phenomena of population ageing, as this case has experienced significant progress in its core activities. These include its complete $\mathrm{CH}$ business ecosystem, including the maturity of information communication technologies (ICT) applied in healthcare and an integrated healthcare system. Through asking 'what' and 'how' questions, a single multi-stage case-study approach aims to explore rich contextual information rather than generalizing principles to a population [61]. A diverse $\mathrm{CH}$ ecosystem of stakeholders including academia, industry, and the government were interviewed to enrich the understanding of how $\mathrm{CH}$ can be improved. Multi-stage interviews were conducted to enhance the depth of the research through iterative data collection.

\subsection{Research Design}

Although Taiwan's case is typical for studying the sustainability of $\mathrm{CH}$, time and distance with regard to collecting and analysing, qualitative data posed a challenge. In order to overcome these issues, several innovative methods to manage data collection were proposed. The principle of agile methodology was used in data collection for its high efficiency with regard to rapid feedback from respondents and adaptability to a fast-changing environment. This methodology fulfils the flexibility characteristic of qualitative research, as suggested by Yin [62].

\subsection{Data Collection}

In this study, the data were collected in a multi-stage setting to progress and adapt to the multi-dimensional nature of the $\mathrm{CH}$ ecosystem. First, exploratory stage interviews $(\mathrm{n}=16)$ were conducted with relevant influencers in the $\mathrm{CH}$ debate to explore the phenomenon. Key influencing stakeholders in the Taiwanese $\mathrm{CH}$ ecosystem were identified in this phase. Second, based on the exploratory stage findings and analysis, and in line with an agile approach, stage one interviews $(n=22)$ were conducted with designated stakeholder groupings $(\mathrm{CH}$ healthcare policymakers and $\mathrm{CH}$ delivery firms). The stage two interviews ( $n=22)$ were conducted one year later and addressed the gaps identified in stage one and two interviews. This was done to discover systematic problems in $\mathrm{CH}$ over time and to review longitudinal changes since the two stages of interviews. These interviews probed 
the $\mathrm{CH}$ problems discovered in the literature, including cost, infrastructure, technology, business sustainability, business model, and collaboration- and communication-related issues.

\subsection{Data Analysis}

The data analysis strategy covers both a thematic and systematic approach to qualitative analysis. The former was organized via deep familiarization with the data collected, leading to the development of major themes. The latter was using NVIVO 10 software through word frequencies to identify key themes. The data were analysed by grouping words or sentences from interviews through word frequency, followed by a more in-depth statistical analysis, which is an approach to present qualitative content in a quantitative way and then to include the development of 'quality' through quantitative changes. Therefore, content analysis and coding can be considered a method of researching content to clarify the meaning behind the content in an objective and systematic way [62]. This analysis adopted a grounded approach. Initially, coded data and themes that were drawn out might change rapidly. The number of new themes emerging gradually diminished and the number of refinements to themes reduced when approaching (theory) saturation. These processes followed the steps of 'describe', 'classify', and 'connect', in line with the literature and applied a constant comparison analysis technique to ensure the quality of data analysis. Data collection and analysis were iterated and reflected parallels to the collection of data until saturation occurred. In addition, the constant referral of up-to-date literature contributed to the data analysis [62].

\subsection{Validity}

As far as the reliability and validity are concerned, the agile methodology (multi-stage) to the data collection and data triangulation are applied to ensure the research quality. The data collected were summarized, confirmed, and discussed in the subsequent interviews until the final interview to ensure reliability and validity. The strengths of this method are that the main interview contents can be confirmed and corrected quickly by experts in the $\mathrm{CH}$ ecosystem. This approach created an environment of a virtual focus group in each interview; bias can be minimized by debate and confirmation within each interview, meaning that not only can this approach obtain the insights of brainstorming but it can also diminish the bias and disadvantages of a focus group [62-64].

\section{Results}

This section summarizes the results of the interview analysis according to thematic structure as shown in Figures 1 and 2. In brief, the exploratory interview confirmed the need for $\mathrm{CH}$ research and provided considerations for improving interviews in the next stage. The two subsequent stages of interview results are presented in the following sub-sections, 4.1-4.4. $\mathrm{CH}^{\prime} \mathrm{s}$ adaption is divided on the merits of the outcomes. Indeed, $\mathrm{CH}$ may contribute to efficiency and cost-effective health delivery. The remote residents are concerned about adapting $\mathrm{CH}$ into their practice due to lack of incentives. This may suggest that the current assumptions in $\mathrm{CH}$ are problematic because they cannot address business sustainability. Therefore, this study employed the essential components of a BM in order to display the results. They are classified into patients' roles, industry chain structure, payment, and technology, as these were indicated as critical areas related to $\mathrm{CH}^{\prime}$ s sustainability. 
- 'Patients' voice[s] of remote areas [are] often being ignored, as they are small in population and many of them are poor in financial status.

- 'Patients/end users are willing to receive free $\mathrm{CH}$ intervention, although they are not always willing to pay for the service.

- 'Patients like the care from the same physician and the same institute, as healthcare is not a pure buying and selling business... It takes time to build up mutual trust.'

- 'Sometimes, they only come to talk with their physician, and they will feel better without taking any medicine.

- 'Our hospital is mainly for offering health services. We have a foundation for our financial support to make it sustainable.' (Head nurse)

- 'It's a religious hospital, we have a foundation and board of presidents, and they usually fully support any innovation in our hospital.' (Head nurse)

- 'They need to highlight our position and impacts in the healthcare ecosystem so that they will not be disregarded.'

- '... we already knew the basic cost would be much cheaper when the service is conduct[ed] here. However, it is terrible [that] we haven't got enough integrated coordinators in $\mathrm{CH}$ business.

- 'I don't understand why they want to make a simple thing more complicated.'

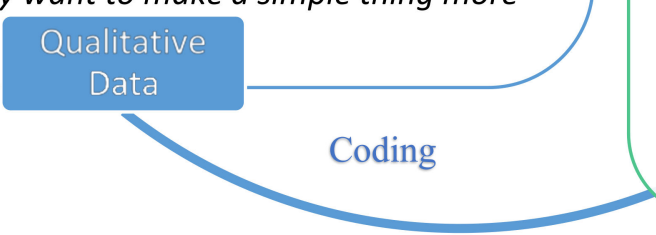

- Invisible role

- Patient-centric

- Value proposition

- Care receiver

- Patient value appraisement,

- Value chains and value networks

- Loosely coupled structure

- 'Push' business strategy

- Imbalance of supply and demand

- Equilibrium

- One-way process

- Willingness to pay for services

- Government sponsored

- Founding ceases

- Participants connecting

- Ubiquitous computing

- Affordability

- Accessibility

- Efficiency and cost effectiveness

- Deprive people of human contact...
Themes

\section{Iterative}

Comparison

- Role of

patients

- Structure of

industry

chain

- Payment

method

- Technology

Figure 1. Results of thematic analysis. 


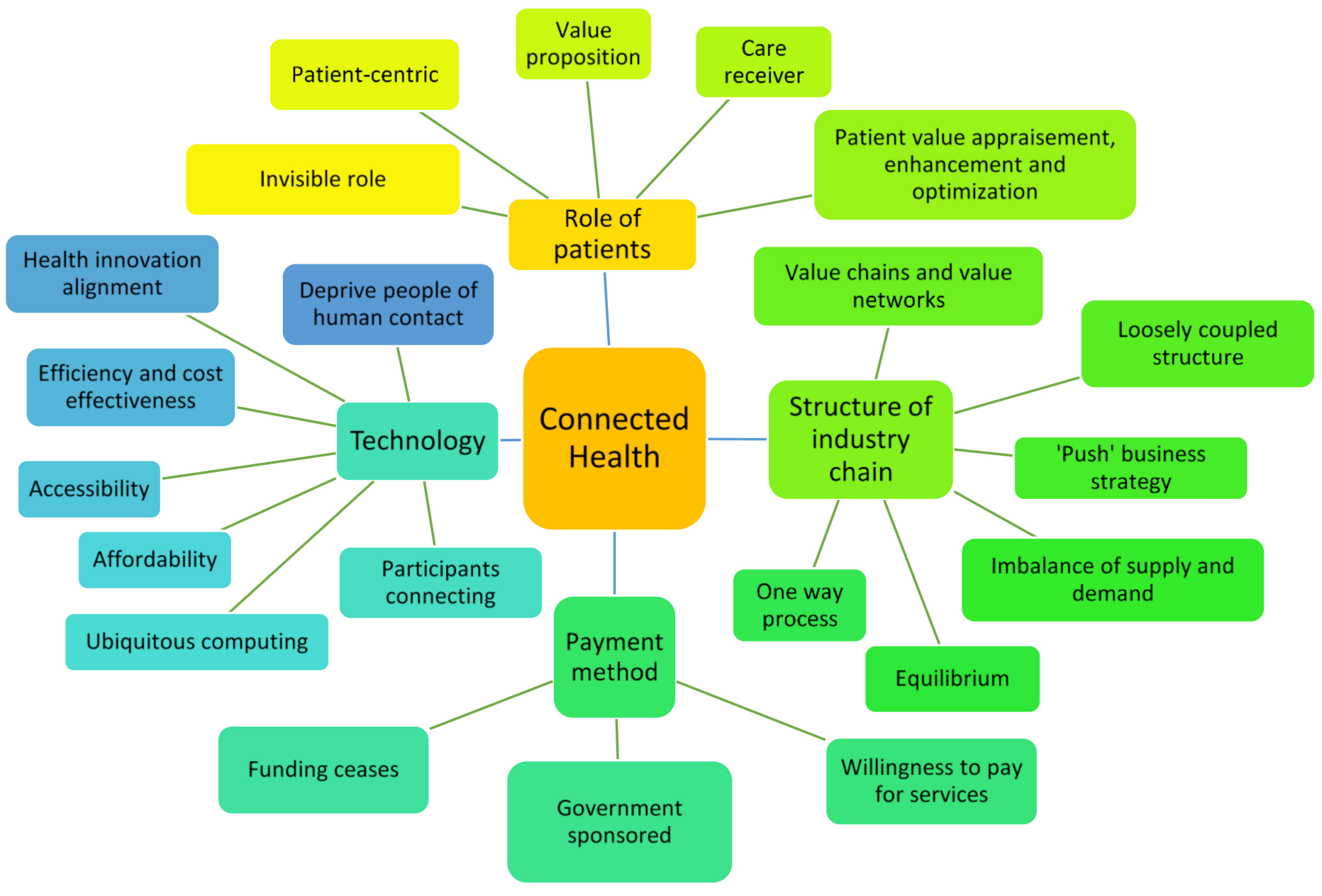

Figure 2. Thematic analysis mapping. 


\subsection{Role of Patients}

Figures 1 and 2 illustrate how interview data is coded and interactively divided into themes. Terms such as 'invisible role'; 'patient-centric model'; 'value proposition'; 'care receiver'; and 'patient value appraisement, enhancement, and optimization' are coded to show the characteristics of the role of patients in the $\mathrm{CH}$ ecosystem. Patients seem to exist as either invisible stakeholders or passive participants, despite their indispensable role. Results demonstrate that the patient's role in healthcare is essential, yet often ignored, as they have little power for influencing decision-making. Although patients have not yet been interviewed in this study due to ethics concerns, their views may be suitably reflected through health professionals and caregivers so as to help them to become less marginalized within the healthcare ecosystem.

'Patients' voices of remote areas are often being ignored, as they are small in population and many of them are poor in financial status.' (General physician)

According to the respondents, patients tend to stick to the physician and caregivers that they are familiar with. Therefore, $\mathrm{CH}$ may be a promising implementation for them to stay 'ageing in place'. This is the concept of patients feeling comfortable growing old in their hometown, a principle which many patients in remote areas follow. Therefore, they are not willing to travel to a famous hospital to see physicians that they are not acquainted with. Care services that are offered by someone that they trust and rely on may be more effective than advanced technologies or more luxurious facilities.

'Patients like the care from the same physician and the same institute, as healthcare is not a pure buying and selling business ... It takes time to build up mutual trust.' (General physician)

'Sometimes, they only come to talk with their physician, and they will feel better without taking any medicine.' (General physician)

Apparently, both industry leaders and policymakers are more interested in those who can bring financial benefits to them. Therefore, the infrastructure of $\mathrm{CH}$ becomes a barrier as the economies of scale is hard to meet in remote areas due to low populations.

'Patients/end users are willing to receive free $\mathrm{CH}$ intervention, although they are not always willing to pay for the service.' (Sales manager)

The strategy of playing a role for remote residents in the healthcare ecosystem is to increase or enhance their importance through added wisdom. This may be done using the resources of remote areas to build up unique competitiveness through differentiation strategies. More and more health care professionals seek to employ media and public relations in order to connect with people through storytelling. These may be effective tools to help with starting to break through the barrier of remote health care.

'They need to highlight our position and impacts in the healthcare ecosystem so that they will not be disregarded.' (General physician)

'Why [can] customers only be consumers? Why they can't be suppliers or even stakeholders?' (General manager)

\subsection{Structure of Industry Chain}

The following codes, identified as 'equilibrium', 'value chains', 'value networks', 'one-way process', 'loosely coupled structure', '" push" business strategy', and 'imbalance of supply and demand' are integrated and merged into the theme identified as 'industry chain structure' as shown in Figures 1 and 2. Companies use value chains and value networks to assist in evaluating supply chain tactics between the company and the customer. In the case of $\mathrm{CH}$, the customers' value is mainly considered 
as providing profits for companies. As soon as potential customers are not willing to pay for the service, it will affect the structure of the industry chain. As far as industrial players are concerned, many companies incorporated $\mathrm{CH}$ into their own businesses without proper preview of business fads or trends. Consequently, few of them will likely be able to survive. Those who successfully identified the market gaps and developed stable relationships with academia, governments, and/or industries are more likely to succeed in market competitions.

'We offer free trial of three months for customers, but many of them return it to us within this period of time, as they would like to try but do not want to pay and we have no control over it.' (Sales manager)

'Many products and services for remote health emerge in the market but patients do not feel like they need them. Consequently, it results [in] an imbalance of supply and demand, which makes it hard for many companies to survive ...' (General manager)

'Without [a] good relationship with academia, government, and industry, you will find it hard to survive in the connected health market.' (General manager)

'Many patients in remote areas have low purchase capability, and they do not have loyalty to connected health's products, so they do not have strong connection with providers.' (Sales manager)

Regarding healthcare facilitators, some institutions are able to significantly improve management of $\mathrm{CH}$ after they experience a learning curve, while others continue to struggle. Contrastingly, certain urban institutions are emergent due to customer demand. These institutions usually demonstrate their ambitions and impressive performance in $\mathrm{CH}$, with the goal of helping customers to receive health service anytime and anywhere.

'We notice that some companies cannot offer user-friendly products, as they do not have sufficient feedback from customers ...' (Head nurse)

'We hope our patients can obtain full-time services. They can get help whenever they need it.' (Head nurse)

\subsection{Payment}

The theme of 'payment method' associates with the codes identified as 'findings cease', 'government sponsored', and 'willingness to pay for services' as shown in Figures 1 and 2. It is seen that $\mathrm{CH}$ is both feasible and desirable in remote areas of Taiwan during exploratory schemes sponsored by government. However, since governmental funding has ceased, the issues of payment method are now becoming a concern. In fact, those who are most in need of $\mathrm{CH}$ tend to have a lower purchase capability for $\mathrm{CH}^{\prime}$ s products and services. Therefore, most of the institutions engaged with $\mathrm{CH}$ are supported by foundations.

'Some remote residents are elderly people living alone, and they are struggling in living; it is hard for them to pay for the remote services.' (Nurse)

'Our hospital is mainly for offering health services. We have a foundation for our financial support to make it sustainable.' (Head nurse)

'It's a religious hospital; we have a foundation and board of presidents, and they usually fully support any innovation in our hospital.' (Head nurse)

\subsection{Technology}

'Technology' is identified as an important theme according to Figures 1 and 2. Results indicate that technology can facilitate the quality of efficiency and cost-effectiveness of $\mathrm{CH}$ for users, as well as 
improve accessibility during the exploratory schemes. What is concerning are the issues of system integration and cross-department communication, which are significant challenges in $\mathrm{CH}$. Without sufficient collaboration among users, the ability to accept and adapt to technology may be compromised. The collaboration and communication-related issues obtained the highest scores, which suggests that they are the most important concerns for interviewees.

'... we already knew the basic cost would be much cheaper when the service is conduct[ed] here. However, it is terrible [that] we haven't got enough integrated coordinators in CH business.' (General physician, director of a health centre)

\section{'I don't understand why they want to make a simple thing more complicated.' (Nurse)}

The results also suggest that technology should be employed in order to help connect people to resources and deliver health and care services rather than for only increasing efficiency and reducing cost. Also, connected care and cross-generation interaction may motivate caregivers and receivers. Overall, the interview results imply that a collaboration which uses technology along with an appropriate BM may be more successful for future healthcare delivery. Therefore, a more holistic $\mathrm{CH}$ industry blueprint and vision would be important for designing and engineering $\mathrm{CH}$ ecosystems in Taiwan. This case study illustrates the need to identify the drivers, structure, content, and pattern of the ideal $\mathrm{CH}$ innovation system, which is discussed in more depth in Section 5.

'What I see is that technology is not about how efficient it is, but how it can serve to connect people from isolation... For me, technology is here to connect, not to deprive people of human contact.' (IT director)

\section{Discussion}

Table 1 shows the limitations of $\mathrm{CH}$ and potential solutions to addressing these limitations according to the results. This section rethinks $\mathrm{CH}$ according to patients' roles, industry chain structure, payment, and technology because the data analysis indicates that these are the key areas relevant to the sustainability of $\mathrm{CH}$ implementation [65-68]. Both the literature review and case study data suggest that the current assumptions in $\mathrm{CH}$ may be problematic because they cannot address $\mathrm{CH}$ business sustainability [69-71]. Therefore, we have analysed, integrated, and redefined the construction of $\mathrm{CH}$ as an innovative BM, focusing on these four essential key areas.

Table 1. Limitations and possible solutions to for key areas of the $\mathrm{CH}$ innovative BM: 'patients' role', 'structure of industry chain', 'payment method', and 'technology'.

\begin{tabular}{|c|c|c|}
\hline CH BM Component & Limitations & Solutions \\
\hline \multirow{7}{*}{ Structure of industry chain } & Invisible role & Patient-centric \\
\hline & Care receiver & Value creator \\
\hline & Resources consumer & Value contributor \\
\hline & Loosely-coupled structure & Tightly-coupled structure \\
\hline & 'Push' business strategy & 'Push and pull' strategy \\
\hline & Imbalance of supply and demand & Equilibrium \\
\hline & One-way process & Two-way cycle \\
\hline \multirow{3}{*}{ Payment method } & Unwilling to pay for services & Willing to exchange for services \\
\hline & Government sponsored & BM innovation \\
\hline & Funding ceases & Value-exchange \\
\hline Technology & $\begin{array}{c}\text { Ubiquitous computing } \\
\text { Low technology adaptivity } \\
\text { Health innovation alignment } \\
\text { Deprive people of human contact }\end{array}$ & $\begin{array}{c}\text { Anytime-anywhere accessibility } \\
\text { Efficiency and cost-effectiveness } \\
\text { Affordability }\end{array}$ \\
\hline
\end{tabular}




\subsection{Rethinking the Role of Patients/Participants}

Results of the data analysis offer several important implications. First, patients, as end users, are willing to receive free $\mathrm{CH}$ intervention, although they are not always willing to pay for the service. This phenomenon suggests that their physical health may not be as important to them as their financial concerns $[47,65,66]$. Furthermore, this indicates that there may be a need to increase the attractiveness of the $\mathrm{CH}$ ecosystem.

Second, patients take on the role of 'passive service receivers' in $\mathrm{CH}$. The traditional care approach is ingrained in healthcare professionals or trained staff. Most health services centre on health professionals rather than patients, although demographic changes and chronic disease management trends have encouraged the implementation of a patient-centric approach $[65,72]$. Patient empowerment only occurs when healthcare professionals acknowledge that patients would like to have more control in their daily care and have autonomous self-management [73,74]. The effectiveness of empowering patients may be influenced by its implementation approach [75].

Third, although patient empowerment is one of the vital objectives of $\mathrm{CH}$, how to activate patients' roles in the $\mathrm{CH}$ ecosystem still remains to be investigated [76]. The literature also suggests that it is important to consider factors ranging from individual sensitivity to cultural differences [77]. This patient-centric concept is growing more important, but a strong motivation for patients to take an active role in the $\mathrm{CH}$ ecosystem is still a challenge. The current $\mathrm{CH}$ assumptions seek to empower patients by encouraging them to monitor their own health. The literature contains multiple and the overlapping meaning of the terms 'empowerment', 'engagement', 'enablement', 'participation', 'involvement', and 'activation' in patient self-care and shared decision-making [78]. This shared decision-making concept comes from the increasing focus on the strategic patient-provider partnership concept [77]. However, the data analysis shows that patients' motivation decreases with time, which suggests that this assumption might need to be reconsidered.

Finally, according to the literature review and data analysis, most $\mathrm{CH}$ products and services focus on how to serve patients, rather than emphasizing on providing them with value, suggesting a need for practitioners to focus more on patient value. In contrast, BM research widely discusses 'value' from the perspective of business suppliers who offer products or services to their target market. This concept defines value as products or services that a company expects to create for the target market segment (TMS). In a BM, the value proposition (VP) plays a crucial role in driving all elements in the model. It is important to consider whether this role (an influential role such as that of the VP) can be found in the $\mathrm{CH}$ ecosystem and whether patients should be considered only as care-receivers, or can be encouraged to be more active in the $\mathrm{CH}$ environment. To resolve these issues, it is important to rethink patients' role as one that can add value to society. In this case, the patient value would be appraised, enhanced, and optimized.

\subsection{Rethinking the Structure of Industry Chain}

Rethinking the industry chain and payment method may be supported by the relationship between supply and demand in the microenvironment, as shown in Figure 3. In this diagram, 'A' refers to the service provider representing the supplier, while ${ }^{\prime} B$ ' and ' $C$ ' refer to the service receiver representing the customer (in this case, the patient). A delivers to $B$ through different economic activities and service payments. $B$ will somehow become a service provider to $C$ in a different economic activity. This cycle is repeated until it returns to A, which ultimately balances the cycle of supply and demand. That is to say, the supply and demand balance are met under the condition that consumers are both suppliers and demanders simultaneously under different contexts [79]. 


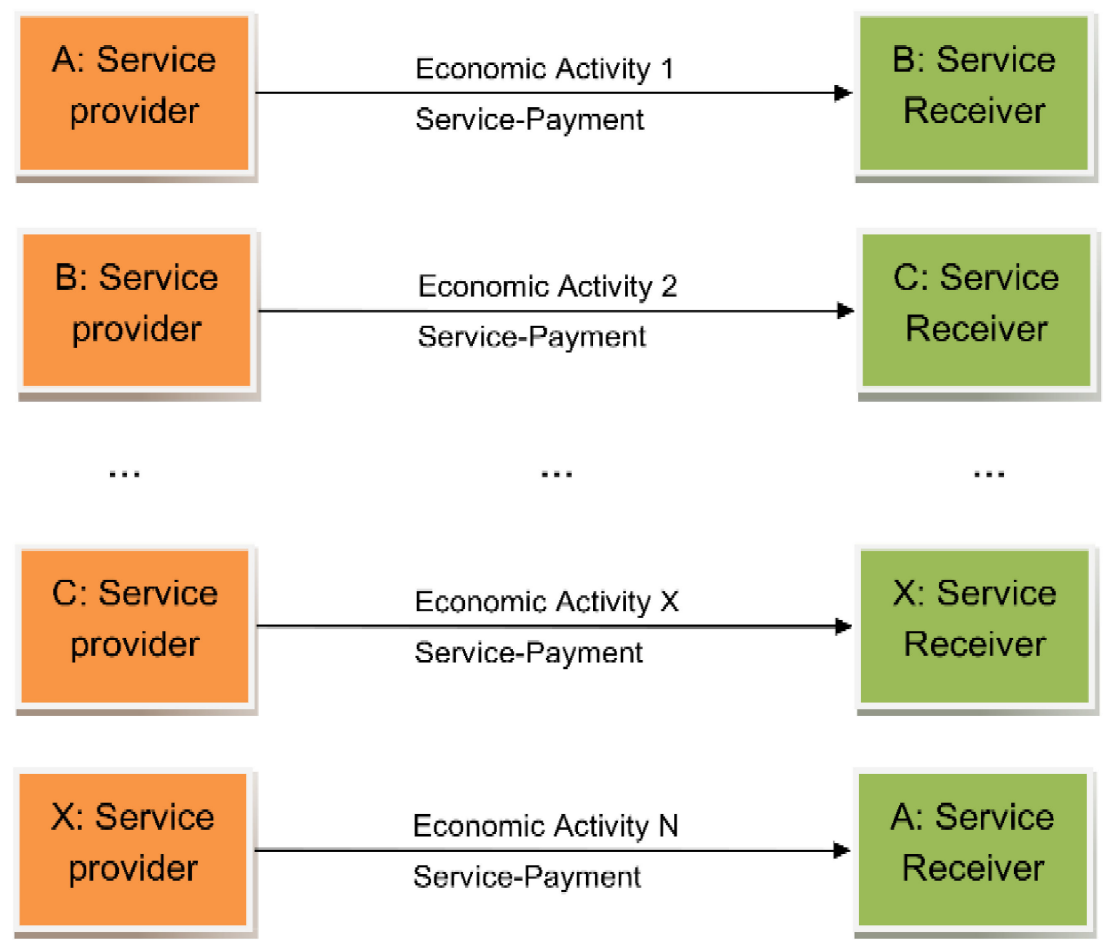

Figure 3. Macroeconomic supply and demand from A's Value Proposition.

In the context of $\mathrm{CH}$, the TMS only has the role of customers, which results in an imbalance between supply and demand, leading to unsustainability. $\mathrm{CH}$ targets older people, chronically ill patients, and patients in remote areas who supply very little but demand a lot, making $\mathrm{CH}$ unsustainable, unless the consumers are both suppliers and demanders. To achieve this goal, it is necessary to create a mechanism to serve as a driving force that can reward both the suppliers and demanders.

The current $\mathrm{CH}$ BM is driven by the internal decision and the relationship between buy and sell contracts, rather than by what the market needs. The issue is that the company manufactures products based on its market predictions, since an incorrect prediction could create a surplus or shortage of goods. In this case, the pull strategy is ideal. Receivers or end-users drive the need for innovation [80]. The manufacturing strategy and end users' value must be incorporated, especially within $\mathrm{CH}$ and this represents a change for the BM. Thus, reviewing patients' roles reveals the need for both strategies, i.e., push and pull.

In the $\mathrm{CH} \mathrm{BM}$, communication between suppliers and customers seem to be simple rather than complex (Figure 4) since its service supply chain tends to go in a single direction. The supplier offers VPs to the TMS. However, there is no requirement for a return in the other direction. Moreover, the business strategy tends to be a push strategy rather than a pull strategy. Because $\mathrm{CH}$ businesses are based on forecast demand and are relatively new, they often adopt a push strategy for their products to generate exposure and a retail channel. Although a successful strategy will usually consist of both push and pull promotional methods, for a new marketer, persuading outlets to purchase and stock products, raising brand awareness, or building valuable word of mouth referrals are essential, thus creating the push strategy.

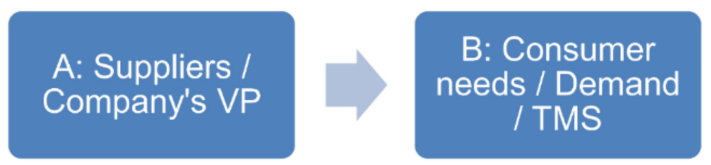

Figure 4. Unsustainable macroeconomic Connected Health process. 
In this $\mathrm{CH}$ case, the equilibrium of supply and demand may be only partial because the lack of intermediate economic activities causes an imbalance. Thus, there is a gap to bridge in order to make $\mathrm{CH}$ businesses sustainable. In fact, all elements in the microenvironment should be a communication cycle at both ends, as shown in Figure 5. There is no return direction communication in the $\mathrm{CH}$ structure, which may cause unsustainability. Therefore, it is essential to create a more reciprocal system to keep the balance of supply and demand in the $\mathrm{CH}$ ecosystem, meaning there is a need to change the current concept of and structure in the TMS in the $\mathrm{CH}$ context. By making these changes, the one-way process will become a two-way cycle, which should significantly increase sustainability. This requires a cooperative model, in which proper solutions can be found for these fundamental issues in $\mathrm{CH}$.

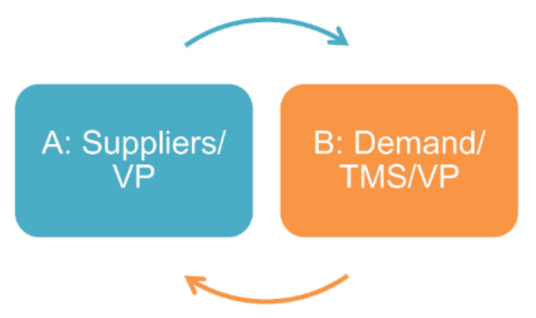

Figure 5. Sustainable Connected Health cycle.

Figure 6 provides an illustration of the interaction of elements in the $\mathrm{CH}$ context [81]. The company offers its VP to the TMS and delivers them through the value chains (VC) and value networks (VN) in the company's competitive strategy (CS) with reasonable profits, or cost and margin (C/M). Yet, it cannot solve the loose connection within the relationship of $\mathrm{CH}$ stakeholders. The literature review also indicates that the value in a BM normally refers to the company's VP, which the company uses in exchange for revenue from customers [67]. Companies use value chains and value networks to assist the supply chain between the company and the customer as shown in Figure 6. In this case, customers' value is mainly considered as providing profits for companies. Although there are some studies indicating the importance of customer inputs in improving or designing products, there is little information on how customers can offer value more actively. In the context of $\mathrm{CH}$, customers are usually referred to as patients. The patient's role in the $\mathrm{CH}$ supply chain is mainly the receiver of the provider's product. The current BM in terms of the $\mathrm{CH}$ attributes and industry chain structure tends to be a 'push' business strategy with a loosely coupled structure, which may lead to unsustainability in the $\mathrm{CH}$ ecosystem. The following sections discuss these tendencies further [47].

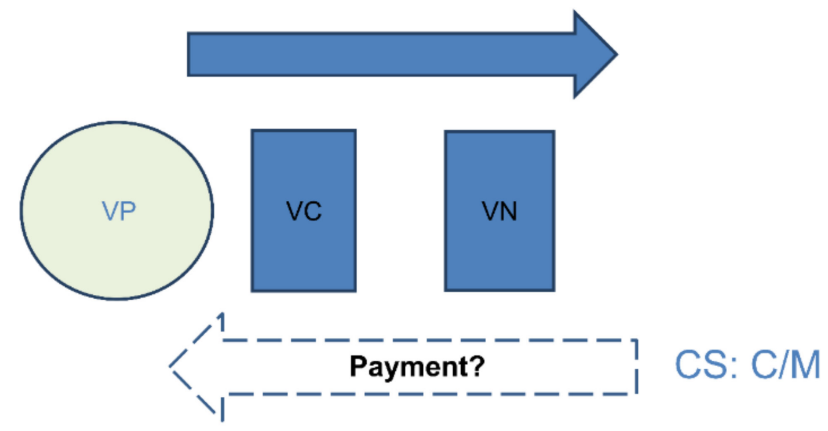

Figure 6. Conventional Connected Health Business Model (source: [81]).

Apart from the issue of supply and demand, $\mathrm{CH}$ has 'loose' connections, which implies that there are no permanent or fixed connections between the players and stakeholders, as shown in Figure 7. This figure illustrates the relationship of the $\mathrm{CH}$ target market segment (CHTMS) among academia, government, and industry wherein these connections are presented using dotted lines. The connections indicate that any party may withdraw from the model at any time due to the loose structure of $\mathrm{CH}$ 
(dotted lines in Figure 7). Commonly, all participants in the $\mathrm{CH}$ business tend to pursue their own personal interests rather than work for a common interest focused on patients. Although it appears to be similar to the quadruple-helix model used by academia, and government, and industry to interact with community and foster economic and social development, Figure 7 highlights a different focus that could be pursued. When compared to the quadruple-helix model, Figure 7 demonstrates $\mathrm{CH}^{\prime}$ s characteristics and discusses its driving force, while the former is concerned more with the relationship among its elements. Specifically, this new model is a customized network with which $\mathrm{CH}$ may portray its value chain; however, the quadruple helix model describes a network of relationships among four stakeholders in terms of knowledge diffusion in general. While the quadruple helix model refers to the relationship between value creation activities and knowledge transfer, Figure 7 further delves into the need for a driving force in the system. Therefore, Figure 7 distinguishes itself by providing a unique model that can explain the network relationship in $\mathrm{CH}^{\prime}$ s ecosystem. The dotted lines connecting all the stakeholders imply a need to shift from loose to tight structures that are strengthened by the value chain. It is also suggested that creating a valuable attraction or VP able to attract all participants is necessary. Based on the fundamental knowledge mentioned earlier, a proposal may be constructed for determining how and what a sustainable $\mathrm{BM}$ for $\mathrm{CH}$ can be. To elucidate these issues, the following section discusses the method proposed for discovering the main drivers for creating value and maintaining a sustainable BM.

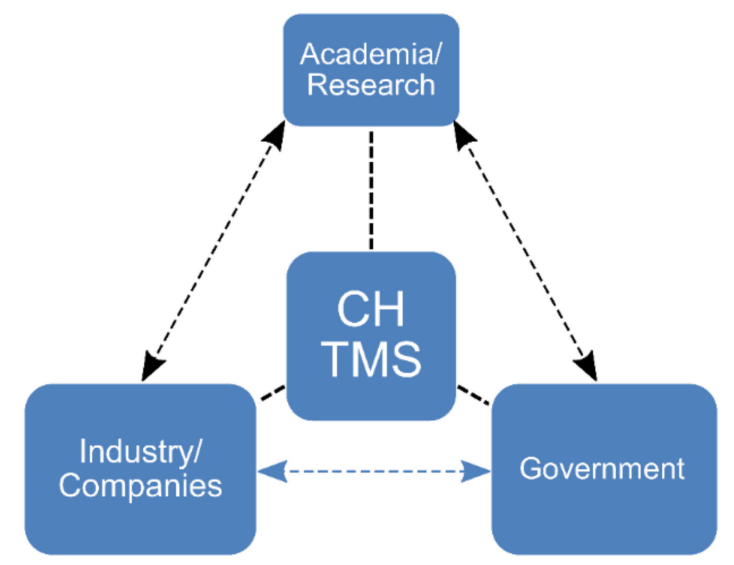

Figure 7. Relationship among Connected Health players/ stakeholders (author's analysis).

\subsection{Rethinking the Payment Method}

In the stage of initiating $\mathrm{CH}$ models, $\mathrm{CH}$ pilot schemes are usually sponsored by governments [81,82]. Although many pilot schemes can show significant results for controlling chronic conditions, the issues regarding cost emerge after funding ceases, which eventually leads to business sustainability issues [67-71]. Thus, the current assumptions about payment methods must be reconsidered. Current $\mathrm{CH}$ BMs also suggest that the payment method is based on the products or services provided. In this case, the TMS pays for the VP that the company offers. However, in the context of $\mathrm{CH}$, the TMS is usually a socially vulnerable group, and it may be a challenge for businesses to maintain their willingness to pay for the service. Nevertheless, in the current $\mathrm{CH}$ model, if they are not willing to pay the premium, $\mathrm{CH}$ businesses may encounter sustainability challenges. Therefore, there may be a need to rethink the potential options to make it sustainable.

\subsection{Rethinking Technology}

Information technology (IT) plays a major role in connecting all participants in the $\mathrm{CH}$ ecosystem and makes the delivery of the VP in the value network more efficient $[79,83]$. The literature review revealed how technology changes many aspects of business practice [16,83-85]. The Internet has helped to convert many processes from lengthy (slow) to digital (fast), and many things are constantly 
digitized at every touchpoint. Consumers, thus, increasingly use technology to track behaviour in their daily lives. Additionally, ubiquitous computing can contribute to the growth in the ranks of a quantified self-treating community. This digital disruption can help people obtain detailed information about their surroundings in a more affordable and accessible way. Technology has proven to be an effective way to make these vital connections, which otherwise might not exist. Technology should not be a robotic mechanical isolator that deprives people of human contact.

In short, there is still confusion when it comes to the role of technology in the $\mathrm{CH}$ ecosystem. Technology may help to improve efficiency and cost-effectiveness, but it may also be able to do more. This was implied by both the literature review and the interviewees; that the disruptive nature of technology can leverage challenges by converging complex processes and making products more affordable $[16,47,85]$. Therefore, the focus should be not only on what technology can do, but also on how people may be able to use technology to better align healthcare innovation with software requirements [86].

\subsection{Analysing, Integrating and Redefining the Business Model's Elements}

Rethinking $\mathrm{CH}$ highlights the value of the TMS and the need for BMI in $\mathrm{CH}$ practice shown as Figure 8. It also suggests that conventional BM needs to change in order to keep $\mathrm{CH}$ sustainable. Although there are no standard elements in a BM, all elements should address the VP, such as what it is, how to deliver it, and how to transform it into profit [48,59]. The elements of Chesbrough's BM [16,48] are employed as an example to analyse $\mathrm{CH}$ BM because the combination of these elements is both value-centric and well-known as a concept. These elements include the VP and establishing unique sources for the $\mathrm{VC}$ and $\mathrm{VN}$, which are dominated by the $\mathrm{CS}$, including a reasonable $\mathrm{C} / \mathrm{M}$. Thus, the VP is delivered to the TMS (Figure 8). Although there are six roles in Chesbrough's BM, they occupy different positions in each microenvironment.

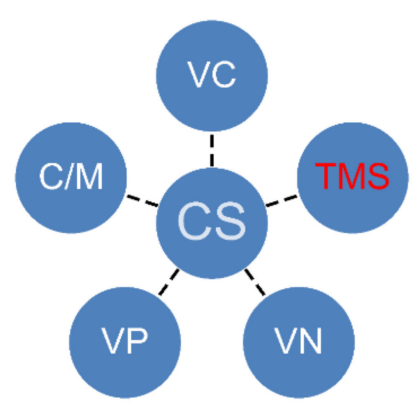

Figure 8. Business Model's elements.

\subsubsection{Integrating and Redefining Value Propositions and the Target Market Segment}

Reimagining the TMS patients' role as no longer being passive receivers but also potential service providers implies a change is needed for the TMS in the current $\mathrm{CH}$ system. Consequently, the TMS is gradually becoming the 'value proposer' with a shift toward customer-centricity. There is a tendency to optimize the total benefits for product and service providers and the TMS/end users. Therefore, this study proposes integrating VP and the TMS to illustrate this tendency. In this integration, VP and TMS are first integrated into 'value' because they include and reflect the value of the TMS. The VP in Chesbrough's BM refers to offering products or services from which companies can create either 'value for users' or 'value for customers (the TMS)' [48]. One is the value proposed by firms and the other is the value receiver in the BM. Value is the similarity that connects these two elements. Value can be considered as a driver to activate the industry chain and create attraction among $\mathrm{CH}$ participants and stakeholders. 


\subsubsection{Integrating and Redefining Competitive Strategy and Cost/Margin}

This study integrates CS and C/M into BMI to reflect the common purpose of generating revenue via a specified and strategic mechanism referring to key success factors for smart and connected health software solution [86,87]. BMI here refers to an innovative mechanism for a business that is strategic, creative, and influential in creating revenue and competitiveness. Rethinking the payment method is also relevant for a company's CS because this also meets the aim of gaining profit from their TMS. However, in the $\mathrm{CH}$ environment, the TMS can be a vulnerable group that has a limited paying capability, which causes a contradiction. Thus, innovative payment methods are required to make a $\mathrm{CH}$ business sustainable.

\subsubsection{Integrating and Redefining the Value Chain and Value Network}

VC and VN are integrated into 'technology' because they act as channels or networks that technology can activate. Rethinking technology means that re-imagining how people use technology to serve their goals is essential. Technology can accommodate many business activities, and it is becoming increasingly efficient and cost-effective. Its disruptive nature enables more affordable and accessible delivery of products or services while maintaining quality.

The VC and VN previously functioned through contracts, logistics, and cash flow. Interests in the VC were allocated through contract agreements, which were carried out via logistics and payment. The VN covers logistics networks and industrial networks (suppliers, manufacturers, brands, distributors, and retailers). In the current $\mathrm{CH}$ system, service providers are able to unite all roles in the industrial network. The previous flow of logistics has transformed into information flow, and cash flow has become virtual. Both information flow and virtual cash flow are entirely delivered through information networks. Therefore, the VC and VN have emerged as a service information network that includes hardware manufacturers, software developers, Internet providers, sensor vendors, and electronic payment systems, which may all be contained within the technology domain. With the development of further technology, such as big data and cloud computing, this kind of integration is likely to happen even faster.

\section{Recommendation: The Value-Centric Business Model Innovation System in Connected Health}

Although previous studies have examined health professional-centred and patient-centred services and the technology push concept, no previous study has integrated the driver, structure, content, and patterns. Therefore, there is a need for a BMI system that can bridge these gaps. The proposed convergence concept in this study is similar to that of the Razorfish model [16], where creativity, media, and technological innovation are rapidly converging within the business environment. Technological advances act as a catalyst for convergence. According to Lord and Velez, the convergence concept means the combination of marketing and technology, which this study translates from the integration of Chesbrough's BM elements into value, BMI, and technology to generate an effective innovation system in $\mathrm{CH}$.

\subsection{Strategies and Processes}

This section demonstrates how value, BMI, and technology could merge into a $\mathrm{CH}$ innovation system. Given the requirement of balancing supply and demand in the $\mathrm{CH}$ environment to implement $\mathrm{CH}$ effectively, the convergence concept requires observations of the complex combinations and their interactions in the intersections of the strategy and business processes. Roles within the $\mathrm{CH}$ ecosystem must have tight connections to act effectively. However, the collective interest in $\mathrm{CH}$ is obscured, resulting in the loose connection among the participants due to self-interest. To encourage collaboration in an economic environment, it is essential to allocate the participants' interests, and their roles must be mutually beneficial for sustainability. Value can be created through the process of re-engineering and measuring incentives. 
Figure 9 shows the convergence of value, BMI, and technology into a VCBMIS, which can be represented sequentially. This innovation system simplifies and integrates the essential elements in a BM to overcome the overemphasis on the details of conventional BM elements. As the literature review indicates, the existing research seems to underline strong cases that may not be repeatable. Re-engineering and the convergence concept enable the duplication of success.

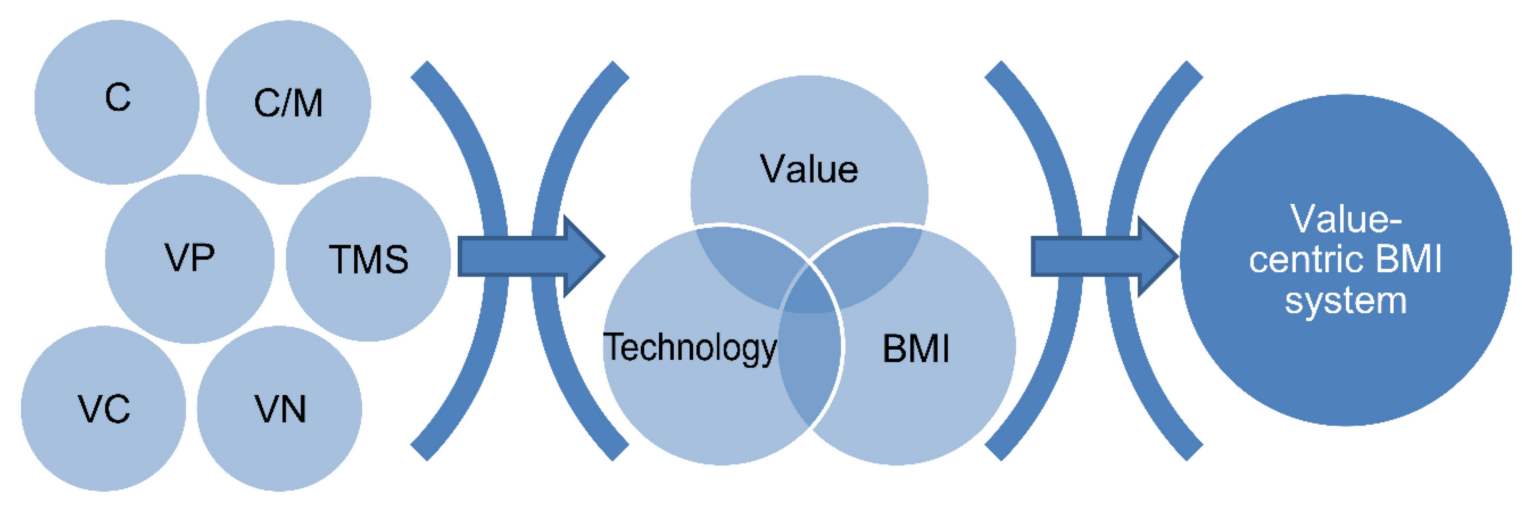

Figure 9. Convergence process illustration.

\subsection{Relationships Between Value, Business Model Innovation and Technology}

In this value-centric innovation system, BMI plays a role of strategy, using technology as a tool to address the objective of value [88]. Here, the value-centric approach indicates the significance of value in this system. Many successful BMs eventually encounter problems with sustainability, and the root cause of these problems is the lack of a driving force at the core of the model. It is important to have a driver in a system to keep it focused and energetic [89-91].

The collaboration of these three elements can be described using the metaphor of 'cooking a meal'. The current products and services are designed based on the companies' assumptions of customers' needs, which is not a sustainable solution. To highlight the nutrition of the meal, it is important to emphasize the ingredients and to suggest solutions based on knowing the 'what'and 'how' of the business. This study contributes by highlighting the need to know the 'what's addition to the 'how's' and 'whys', of the model itself.

Although value is at the core of this system, it would not be very powerful without the inputs of creative culture, innovative spirit, and advanced technologies. Especially in dealing with systematic failure within healthcare, it is not possible to ignore the systematic architecture. Thus, the value provides the vision and power to reconfigure the elements of the BMI system using technology as a key tool.

BMI should be strategic and innovative so that the firm can decide whether to take the role of a leader or a follower [91]. In terms of the challenges of an ageing population, many seek to invent products for older adults, particularly those with chronic conditions. However, Murata [92] believes that creating job opportunities for older adults is the key to entering this market. In terms of the strategic management of BMI, the concept of competitor-alliance must be applied, meaning that if it is impossible to conquer competitors, then forming an alliance or a partnership is an option to turn the competitors into stakeholders [93]. This study highlights the possibilities of transforming consumers of resources into benefits-sharing stakeholders; and notes that value, technology, and BMI are all essential to achieving this goal [94].

Technology is not only a tool for delivering value, but also allows a leading role for BMI in the market through innovative business approaches for the unfulfilled promises of health information technology [95]. This is the real value of applying technology and clinical pathway support systems [96]. In this example, technology has significantly disrupted the function of a conventional BM, leading to its essential reconfiguration. The key to success is making the best use of current technologies in tandem with the convergence concept in developing a more sustainable BMI. In addition, innovation 
requires team spirit and individual genius. This value-centric system requires the integration of the three individual elements of value, BMI, and technology to achieve sustainability.

\section{Conclusions}

$\mathrm{CH}$ is proposed to manage challenges faced in an ageing society and to sustain the medical care system. However, whether it is a fad or a trend is still debatable. This study offers insights that help build a sustainable system that will benefit both patients and society through rethinking $\mathrm{CH}^{\prime}$ s structure and participants in the ecosystem. It provides opportunities for differentiation that respond to the challenges of shortened life cycles and sustains competitive advantages.

This study also suggests that academics should be proactive in finding new ways to improve the structure of the supply chains/driving forces behind BMI in the $\mathrm{CH}$ context, while practitioners should not base the service BM on technology-orientated products that they develop. Moreover, the service supply chain must first represent customer value needs in the context of innovation users and industry should synthesize their offerings with their target segment's contributions. Furthermore, technology should be applied to promote and deliver care to the TMS rather than creating isolation. Lastly, governments should take the lead in building a platform allowing the integration of relevant databases between all participants and monitor financial engagement in such platform to ensure that it appropriately protects the rights of each party, thus reducing ethical concerns through the imposed policies. This system can help guide $\mathrm{CH}$ business strategies and applications based on value categorization, which the authors plan to develop in future work.

Author Contributions: Conceptualization, Writing - original draft, Data curation, Formal analysis, Investigation and Methodology are contributed by S.C.-I.C.; Funding acquisition and Supervision are contributed by R.H.; Validation, Software and Visualization are contributed by C.L. All authors have read and agreed to the published version of the manuscript.

Funding: This research was funded by the Huaqiao University High-level Talent Research Startup Project and The Straits Postdoctoral Fellowship Funding Program in 2018, Fujing Financial office no. [2017] 32, grant number 605 50X18137, and The APC was funded by Huaqiao University.

Acknowledgments: This research was supported by Academic: Ulster University; industry: Far EasTone Telecommunications and Huede technology; health sector: Taoyuan Fu Hsing Township Health station, Changhua Christian Hospital Telecare Health service center, Show-Chwan Hospital, Taiwan University Hospital Telehealth Centre, and Mennonite Christian Hospital.

Conflicts of Interest: The authors declare no conflict of interest.

\section{References}

1. Caulfield, B.M.; Donnelly, S.C. What is connected health and why will it change your practice? QJM Int. J. Med. 2013, 106, 703-707. [CrossRef] [PubMed]

2. Skouby, K.E.; Kivimäki, A.; Haukiputo, L.; Lynggaard, P.; Windekilde, I.M. Smart cities and the ageing population. In Proceedings of the 32nd Meeting of WWRF, Marrakech, Morocco, 20-22 May 2014.

3. Lehoux, P.; Battista, R.N.; Lance, J.M. Telehealth: Passing fad or lasting benefits? Can. J. Public Health 2000, 91, 277-280. [CrossRef] [PubMed]

4. Goesling, B.; Firebaugh, G. The trend in international health inequality. Popul. Dev. Rev. 2004, 30, 131-146. [CrossRef]

5. Dwivedi, A.N.; Bali, R.K.; Naguib, R.N. Telemedicine: The next healthcare delivery medium: Fad or future? Int. J. Healthc. Technol. Manag. 2007, 8, 226-249. [CrossRef]

6. Kim, T.H.; Lee, H.H. Is telemedicine a worldwide trend? Arch. Gynecol. Obstet. 2014, 289, 925-926. [CrossRef]

7. Househ, M.; Borycki, E.M.; Kushniruk, A.W.; Alofaysan, S. mHealth: A passing fad or here to stay. In Telemedicine and E-Health Services, Policies, and Applications: Advancements and Developments; IGI Global: Hershey, PA, USA, 2012.

8. Burritt, R.L.; Schaltegger, S. Sustainability accounting and reporting: Fad or trend? Account. Audit. Account. J. 2010, 23, 829-846. [CrossRef] 
9. Everard, M.; Longhurst, J.W. Reasserting the primacy of human needs to reclaim the 'lost half' of sustainable development. Sci. Total Environ. 2018, 621, 1243-1254. [CrossRef]

10. Schaltegger, S.; Hansen, E.G.; Lüdeke-Freund, F. Business models for sustainability: Origins, present research, and future avenues. Organ. Environ. 2016, 29, 3-10.

11. Schaltegger, S.; Lüdeke-Freund, F.; Hansen, E.G. Business cases for sustainability: The role of business model innovation for corporate sustainability. Int. J. Innov. Sustain. Dev. 2012, 6, 95-119. [CrossRef]

12. Håkansson, S.; Gavelin, C. What do we really know about the cost-effectiveness of telemedicine? J. Telemed. Telecare 2000, 6, 133-136. [CrossRef]

13. Mueller, K.J.; Potter, A.J.; MacKinney, A.C.; Ward, M.M. Lessons from tele-emergency: Improving care quality and health outcomes by expanding support for rural care systems. Health Aff. 2014, 33, 228-234. [CrossRef] [PubMed]

14. Das, A.K.; Goswami, A. A secure and efficient uniqueness-and-anonymity-preserving remote user authentication scheme for connected health care. J. Med. Syst. 2013, 37, 9948. [CrossRef] [PubMed]

15. Lega, F.; Prenestini, A.; Spurgeon, P. Is management essential to improving the performance and sustainability of health care systems and organizations? A systematic review and a roadmap for future studies. Value Health 2013, 16, S46-S51. [CrossRef] [PubMed]

16. Lord, B.W.; Velez, R. Converge: Transforming business at the intersection of marketing and technology; John Wiley \& Sons: Hoboken, NJ, USA, 2016.

17. McCarthy, J.F.; Blow, F.C.; Valenstein, M.; Fischer, E.P.; Owen, R.R.; Barry, K.L.; Hudson, T.J.; Ignacio, R.V. Veterans Affairs Health System and mental health treatment retention among patients with serious mental illness: Evaluating accessibility and availability barriers. Health Serv. Res. 2007, 42, 1042-1060. [CrossRef]

18. Turcu, C.E.; Turcu, C.O. Internet of things as key enabler for sustainable healthcare delivery. Procedia Soc. Behav. Sci. 2013, 73, 251-256. [CrossRef]

19. Kanuganti, S.; Sarkar, A.K.; Singh, A.P.; Arkatkar, S.S. Quantification of accessibility to health facilities in rural areas. Case Stud. Transp. Policy 2015, 3, 311-320. [CrossRef]

20. Myers, K.; Comer, J.S. The case for telemental health for improving the accessibility and quality of children's mental health services. J. Child Adolesc. Psychopharmacol. 2016, 26, 186-191. [CrossRef]

21. Ouhbi, S.; Fernández-Alemán, J.L.; Toval, A.; Rivera Pozo, J.; Idri, A. Sustainability requirements for connected health applications. J. Softw. Evol. Proc. 2018, 30, e1922. [CrossRef]

22. Kvedar, J.; Coye, M.J.; Everett, W. Connected health: A review of technologies and strategies to improve patient care with telemedicine and telehealth. Health Aff. 2014, 33, 194-199. [CrossRef]

23. Weeks, W.B.; Kazis, L.E.; Shen, Y.; Cong, Z.; Ren, X.S.; Miller, D.; Lee, A.; Perlin, J.B. Differences in health-related quality of life in rural and urban veterans. Am. J. Public Health 2004, 94, 1762-1767. [CrossRef]

24. Cook, P. Infrastructure, rural electrification and development. Energy Sustain. Dev. 2011, 15, 304-313. [CrossRef]

25. Singh, R.; Mathiassen, L.; Stachura, M.E.; Astapova, E.V. Sustainable rural telehealth innovation: A public health case study. Health Serv. Res. 2010, 45, 985-1004. [CrossRef] [PubMed]

26. Casey, M.; Hayes, P.S.; Heaney, D.; Dowie, L.; ÓLaighin, G.; Matero, M.; Hun, S.; Knarvik, U.; Alrutz, K.; Eadie, L.; et al. Implementing transnational telemedicine solutions: A connected health project in rural and remote areas of six Northern Periphery countries. Eur. J. Gen. Pract. 2013, 19, 52-58. [CrossRef] [PubMed]

27. Bansal, P.; DesJardine, M.R. Business sustainability: It is about time. Strateg. Organ. 2014, 12, 70-78. [CrossRef]

28. Apker, J.; Propp, K.M.; Ford, W.S.; Hofmeister, N. Collaboration, credibility, compassion, and coordination: professional nurse communication skill sets in health care team interactions. J. Prof. Nurs. 2006, 22, 180-189. [CrossRef] [PubMed]

29. Evans, J.; Pettus, D.; Higgins, R. Method and System for Communication and Collaboration between a Patient and Healthcare Professional. U.S. Patent No. 8,010,717, 30 August 2011.

30. Bremmers, H.J.; Van der Meulen, B.M.; Purnhagen, K. Multi-stakeholder responses to the European Union health claims requirements. J. Chain Netw. Sci. 2013, 13, 161-172. [CrossRef]

31. Lavery, J.V. Building an evidence base for stakeholder engagement. Science 2018, 361, 554-556. [CrossRef]

32. Gawanmeh, A. Open issues in reliability, safety, and efficiency of connected health. In Proceedings of the IEEE First International Conference on Connected Health: Applications, Systems and Engineering Technologies (CHASE), Washington, DC, USA, 27-29 June 2016; pp. 1-6. 
33. Jia, L.; Tan, Y.; Han, F.; Zhou, Y.; Zhang, C.; Zhang, Y. Factors affecting chinese young adults' acceptance of connected health. Sustainability 2019, 11, 2376. [CrossRef]

34. Agboola, S.O.; Bates, D.W.; Kvedar, J.C. Digital health and patient safety. JAMA 2016, 315, 1697-1698. [CrossRef]

35. Chen, S.C.; Liu, C. Factors Influencing the Application of Connected Health in Remote Areas, Taiwan: A Qualitative Pilot Study. Int. J. Environ. Res. Public Health 2020, 17, 1282. [CrossRef]

36. Sadler, A.G.; Booth, B.M.; Mengeling, M.A.; Doebbeling, B.N. Life span and repeated violence against women during military service: Effects on health status and outpatient utilization. J. Womens Health 2004, 13, 799-811. [CrossRef] [PubMed]

37. Madeo, F.; Eisenberg, T.; Pietrocola, F.; Kroemer, G. Spermidine in health and disease. Science 2018, 359, eaan2788. [CrossRef] [PubMed]

38. Collins, B. Big data and health economics: Strengths, weaknesses, opportunities and threats. Pharmacoeconomics 2016, 34, 101-106. [CrossRef] [PubMed]

39. Turner, C.F.; Rogers, S.M.; Hendershot, T.P.; Miller, H.G.; Thornberry, J.P. Improving representation of linguistic minorities in health surveys. Public Health Rep. 1996, 111, 276. [PubMed]

40. Lindley, K.J.; Glaser, D.; Milla, P.J. Consumerism in healthcare can be detrimental to child health: Lessons from children with functional abdominal pain. Arch. Dis. Child. 2005, 90, 335-337. [CrossRef] [PubMed]

41. Cohen, S.B.; Grote, K.D.; Pietraszek, W.E.; Laflamme, F. Increasing consumerism in healthcare through intelligent information technology. Am. J. Manag. Care 2010, 16, SP37-SP43.

42. Fischer, S. Patient choice and consumerism in healthcare: Only a mirage of wishful thinking. In Challenges and opportunities in health care management; Springer: Cham, Switzerland, 2015; pp. 173-184.

43. Umberson, D.; Karas Montez, J. Social relationships and health: A flashpoint for health policy. J. Health Soc. Behav. 2010, 51, S54-S66. [CrossRef]

44. Chouvarda, I.G.; Goulis, D.G.; Lambrinoudaki, I.; Maglaveras, N. Connected health and integrated care: Toward new models for chronic disease management. Maturitas 2015, 82, 22-27. [CrossRef]

45. Karamitsios, K.; Orphanoudakis, T. Efficient IoT data aggregation for connected health applications. In Proceedings of the 2017 IEEE Symposium on Computers and Communications (ISCC), Heraklion, Greece, 3 July 2017; IEEE: Piscataway, NJ, USA, 2017; pp. 1182-1185.

46. Fagerberg, J. Innovation, technology and the global knowledge economy: Challenges for future growth. In Proceedings of the Green Roads to Growth Project and Conference, Copenhagen, Denmark, 1 March 2006.

47. Christensen, C.M.; Grossman, J.H.; Hwang, J. The role of disruptive technology and business model innovation in making products and services affordable and accessible. The Innovator's Prescription: A Disruptive Solution for Healthcare; McGraw-Hill: New York, NY, USA, 2009; pp. 1-36.

48. Chesbrough, H. Business model innovation: Opportunities and barriers. Long Range Plann. 2010, 43, $354-363$. [CrossRef]

49. Tidd, J.; Bessant, J. Strategic Innovation Management; John Wiley \& Sons: Hoboken, NJ, USA, 2014.

50. Omachonu, V.K.; Einspruch, N.G. Innovation in healthcare delivery systems: A conceptual framework. Public Sector Innov. J. 2010, 15, 1-20.

51. Nixon, J.; Ulmann, P. The relationship between health care expenditure and health outcomes. Eur. J. Health Econ. 2006, 7, 7-18. [CrossRef] [PubMed]

52. Cuckler, G.A.; Sisko, A.M.; Poisal, J.A.; Keehan, S.P.; Smith, S.D.; Madison, A.J.; Wolfe, C.J.; Hardesty, J.C. National health expenditure projections, 2017-2026: Despite uncertainty, fundamentals primarily drive spending growth. Health Aff. 2018, 37, 482-492. [CrossRef] [PubMed]

53. Herzlinger, R.E. Why innovation in health care is so hard Harvard business review. Harv. Bus. Rev. 2006, 84, 58. [PubMed]

54. Christensen, C.M.; Grossman, J.H.; Hwang, J. The innovator's Prescription: A Disruptive Solution for Health Care; Wiley-Blackwell: New York, NY, USA, 2009.

55. Gupte, G.; Vimalananda, V.; Simon, S.R.; DeVito, K.; Clark, J.; Orlander, J.D. Disruptive innovation: Implementation of electronic consultations in a Veterans Affairs health care system. JMIR Med. Inform. 2016, 4, e6. [CrossRef] [PubMed]

56. Galea, S. Will disruptive innovation in health care improve the health of populations? Milbank Q. 2018, 96, 619-622. [CrossRef] [PubMed] 
57. Christensen, C.; Waldeck, A.; Fogg, R. How disruptive innovation can finally revolutionize healthcare. Ind. Horiz. 2017, 2017, 1-28.

58. De Bes, F.T.; Kotler, P. Winning at Innovation: The A-to-F Model; Palgrave Macmillan: London, UK, 2011.

59. Zott, C.; Amit, R. Business model innovation: How to create value in a digital world. MIR 2017, 9, 18-23. [CrossRef]

60. Glesne, C. Becoming Qualitative Researchers: An Introduction; Pearson, One Lake Street: Upper Saddle River, NJ, USA, 2016; p. 07458.

61. Zainal, Z. Case study as a research method. J. Kemanus. 2007, 5, 1-6.

62. Yin, R.K. Qualitative research from start to finish; Guilford Publications: New York, NY, USA, 2015.

63. Maruping, L.M.; Venkatesh, V.; Agarwal, R. A control theory perspective on agile methodology use and changing user requirements. Inf. Syst. Res. 2009, 20, 377-399. [CrossRef]

64. Livermore, J.A. Factors that significantly impact the implementation of an agile software development methodology. JSW 2008, 3, 31-36. [CrossRef]

65. Frist, W.H. Connected health and the rise of the patient-consumer. Health Affairs 2014, 191-193. [CrossRef] [PubMed]

66. O'leary, P.; Carroll, N.; Clarke, P.; Richardson, I. Untangling the complexity of connected health evaluations. In Proceedings of the 2015 International Conference on Healthcare Informatics, Dallas, TX, USA, 21 October 2015; IEEE: Piscataway, NJ, USA, 2015; pp. 272-281.

67. Carroll, N.; Richardson, I. Mapping a careflow network to assess the connectedness of connected health. Health Inform. J. 2019, 25, 106-125. [CrossRef] [PubMed]

68. Argent, R.; Daly, A.; Caulfield, B. Patient involvement with home-based exercise programs: can connected health interventions influence adherence? JMIR mHealth uHealth 2018, 6, e47. [CrossRef] [PubMed]

69. Kvedar, J.C.; Hwang, J.; Moorhead, T.; Orlov, L.M.; Ubel, P.A. Up from crisis: Overhauling healthcare information, payment, and delivery in extraordinary times. Dialogue with featured speakers from the 6th annual connected health symposium. Telemed. E Health 2009, 15, 634-641. [CrossRef] [PubMed]

70. Seo, M.; Kim, J.H.; David, P. Always connected or always distracted? ADHD symptoms and social assurance explain problematic use of mobile phone and multicommunicating. J. Comput. Mediat. Commun. 2015, 20, 667-681. [CrossRef]

71. Van Velthoven, M.H.; Powell, J.; Powell, G. Problematic smartphone use: Digital approaches to an emerging public health problem. Dig Heal 2018, 4, 1-9. [CrossRef]

72. Vezyridis, P.; Timmons, S. On the adoption of personal health records: some problematic issues for patient empowerment. Ethics Inf. Technol. 2015, 17, 113-124. [CrossRef]

73. Sharma, N.S. Patient centric approach for clinical trials: Current trend and new opportunities. Perspect. Clin. Res. 2015, 6, 134. [CrossRef]

74. Johnston, A.C.; Worrell, J.L.; Di Gangi, P.M.; Wasko, M. Online health communities: An assessment of the influence of participation on patient empowerment outcomes. Inf. Technol. People 2013, 26, 213-235. [CrossRef]

75. Dandage, S.; Huber, J.; Janki, A.; Niemann, U.; Pryss, R.; Reichert, M.; Harrison, S.; Vessala, M.; Schlee, W.; Probst, T.; et al. Patient empowerment through summarization of discussion threads on treatments in a patient self-help forum. In Precision Medicine Powered by pHealth and Connected Health; Springer: Singapore, Singapore, 2018; pp. 229-233.

76. Anderson, R.M.; Funnell, M.M. Patient empowerment: myths and misconceptions. Patient Educ. Couns. 2010, 79, 277-282. [CrossRef] [PubMed]

77. Asimakopoulou, K.; Newton, P.; Sinclair, A.J.; Scambler, S. Health care professionals' understanding and day-to-day practice of patient empowerment in diabetes: Time to pause for thought? Diabetes Res. Clin. Pract. 2012, 95, 224-229. [CrossRef] [PubMed]

78. Chen, J.; Mullins, C.D.; Novak, P.; Thomas, S.B. Personalized strategies to activate and empower patients in health care and reduce health disparities. Health Educ. Behav. 2016, 43, 25-34. [CrossRef] [PubMed]

79. Fumagalli, L.P.; Radaelli, G.; Lettieri, E.; Masella, C. Patient empowerment and its neighbours: Clarifying the boundaries and their mutual relationships. Health Policy 2015, 119, 384-394. [CrossRef]

80. Keown, O.P.; Parston, G.; Patel, H.; Rennie, F.; Saoud, F.; Al Kuwari, H.; Darzi, A. Lessons from eight countries on diffusing innovation in health care. Health Aff. 2014, 33, 1516-1522. [CrossRef] 
81. Chen, S.C.; Kharabsheh, R.A. The Link between innovation and prosperity: how to manage knowledge for the individual's and society's benefit from big data governance? In Big Data Governance and Perspectives in Knowledge Managemen; IGI Global: Hershey, PA, USA, 2019; pp. 200-217.

82. Taylor, T. The Instant Economist: Everything You Need to Know About How the Economy Works; Penguin: New York, NY, USA, 2012.

83. Cho, S.; Mathiassen, L.; Gallivan, M. Crossing the diffusion chasm: From invention to penetration of a telehealth innovation. Inf. Technol. People 2009, 22, 351-366. [CrossRef]

84. Oftedal, E.M.; Foss, L.; Iakovleva, T. Responsible for responsibility? A study of digital e-health startups. Sustainability 2019, 11, 5433. [CrossRef]

85. Hall, A.; Walton, G. Information overload within the health care system: A literature review. Health Info. Libr. J. 2004, 21, 102-108. [CrossRef]

86. Carroll, N.; Richardson, I. Aligning healthcare innovation and software requirements through design thinking. In Proceedings of the 2016 IEEE/ACM International Workshop on Software Engineering in Healthcare Systems (SEHS), Austin, TX, USA, 14-15 May 2016; IEEE: Piscataway, NJ, USA, 2016; pp. 1-7.

87. Carroll, N. Key success factors for smart and connected health software solutions. Computer 2016, 49, $22-28$. [CrossRef]

88. O'Dwyer, M.; Gilmore, A. Value and alliance capability and the formation of strategic alliances in SMEs: The impact of customer orientation and resource optimisation. J. Bus. Res. 2018, 87, 58-68. [CrossRef]

89. Nicolini, D. Medical innovation as a process of translation: a case from the field of telemedicine. Br. J. Manag. 2010, 21, 1011-1026. [CrossRef]

90. Rifkin, J. The Zero Marginal Cost Society: The Internet of Things, the Collaborative Commons, and the Eclipse of Capitalism; St. Martin's Press: New York, NY, USA, 2014.

91. Chesbrough, H.; Crowther, A.K. Beyond high tech: Early adopters of open innovation in other industries. $R$ D Manag. 2006, 36, 229-236. [CrossRef]

92. Murata, Y. Mathematics for Stability and Optimization of Economic Systems; Academic Press: Cambridge, MA, USA, 2014.

93. Chua, S.; Duffy, A. Friend, foe or frenemy? Traditional journalism actors' changing attitudes towards peripheral players and their innovations. Media Commun. 2019, 7, 112-122. [CrossRef]

94. Harting, T.R.; Harmeling, S.S.; Venkataraman, S. Innovative stakeholder relations: When 'ethics pays' (and when it doesn't). Bus. Ethics Q. 2006, 16, 43-68. [CrossRef]

95. Kellermann, A.L.; Jones, S.S. What it will take to achieve the as-yet-unfulfilled promises of health information technology. Health Aff. 2013, 32, 63-68. [CrossRef]

96. O'Leary, P.; Carroll, N.; Richardson, I. The practitioner's perspective on clinical pathway support systems. In Proceedings of the 2014 IEEE International Conference on Healthcare Informatics, Verona, Italy, 15-17 September 2014; IEEE: Piscataway, NJ, USA, 2014; pp. 194-201. 